\title{
Effect of Groundnut Sucking Bug (Rhyparochromus Littoralis Dist.) (Heteroptera: Lygaeidae) On Kampala Groundnut Cultivar in Yola, Nigeria
}

\author{
${ }^{1}$ Samaila, A. E. And ${ }^{2}$ Malgwi, A. M. \\ ${ }^{1,2}$ Department of Crop Protection, Federal University of Technology, Yola, P. M. B. 2076, Yola - Adamawa \\ State
}

\begin{abstract}
The study on the groundnut-sucking bug (Rhyparochromus littoralis Dist) was carried out at the Teaching and Research Farms of the Modibbo Adama University of Technology Yola in order to establish its abundance and damage potential on groundnut in the 2009 and 2010 cropping seasons. The experiment was a split plot design (SPD) with three replications. The main treatments were the groundnut cultivar, while the subtreatments are the harvesting days. Results showed that abundance of $R$. littoralis was at 28 days after harvesting (DAH) with a least mean of 1135.33 and 1274.00 at 3 days after harvesting and 5036.33 and 5079.67 as the highest mean abundance in 2009 and 2010 respectively. Results showed that prolonging the number of days for groundnut to dry in the field creates convenient environment for breeding and multiplication while continuous damage is exerted on the pods on the field.
\end{abstract}

Key Words: incidence, distribution, abundance, damage potential, alternate host

\section{Introduction}

Groundnut (Arachis hypogea Linn) belongs to the family Leguminosae and is one of the most important oil seed crop in the world (Brink \& Belay, 2006; ICRISAT, 2009). The groundnuts have been recognized around the world by an assortment of colorful names. While Americans call it peanut, it is known by several other names such as African nut, Chinese nut, Manila nut, Kipper nut, Hawks nut, Jarnut, Earth chestnut, Monkey nut, Goobers pear, Ground pea, and Ground bean (Johnson, et al., 1981). Locally in Nigeria especially in the north where it is cultivated it is known as 'gyada' in Hausa, 'okpa' in Igbo, 'epa' in Yoruba (Wood and Ambridge, 1996) while it is also known as 'wada' in Kilba and Bura and the Yungur speaking people refer to it as 'shiyara'.

Although peanut have relatively gained importance recently the origin of the crop dates back to $350 \mathrm{~B}$ C (Hammons, 1994). With a humble beginning, groundnuts have gained prominence for their economic importance and nutritional value on a global scale and are now cultivated throughout the world (Shakarappa, et al., 2009). The main use of groundnut is as a source of edible oil, but it's an important food crop to man, however in spite of its importance to man, groundnut has a lot of pests in the field. The most damaging postharvest insect pest of groundnut include the groundnut brunchid (Caryedon serratus Olivier) almond moth (Ephestia cautella), Indian meal moth (Plodia interpunctella), khapra beetle (Togoderma granarium Everts) and Elasmolomus sordidus (Fabricus) in Africa and Asia (Dick, 1987) amongst many others.

However, one of the most notorious posts-harvest field pests of groundnut is the pod sucking Lygaeid bug ( $R$. littoralis) [Heteroptera: Lygyaedae] of which both nymphs and adults cause serious damage on harvested groundnut in Nigeria and India (Malgwi and Onu, 2004; ICRISAT, 2008). The bug is popularly known in the Northern part of Nigeria as 'shamai' by the Hausa speaking people while the Yungur speaking people of Adamawa State refer to its as ' $o f f a$ '. In the field, the females lay their eggs in the soil or on groundnut haulms and in storage eggs are laid loosely among the groundnut or on sacks (ICRISAT, 2008). ICRISAT (2008) further stated that all stages of development of this insect attack pods as well as kernels (seeds). This bug feeds on pods left to dry in the field or on stored pods. In storage, this bug feeds on seeds, perforating the pod with their stylate. This causes the seeds to shrivel and increase the free fatty acid content of the oil thereby producing a rancid flavor, thus affecting the quality of groundnut.

Malgwi and Onu (2004) reported that the detailed life history of this pest is not known, but they were found in large chambers, under harvested groundnut left to dry before picking on the field. Such groundnuts, when left after harvesting for a week turns out to have small, shrunken seeds, the testa often turning yellow. They further, stressed that there is no detailed research on the oil content or the nutritive value loss, which has not been carried out. Lots of research on the insect pest of groundnut and their assessment on its damage have been done by several Researchers, (Slater, 1972, Malgwi and Onu, 2004). However, only few of these earlier researchers mentioned $R$. littoralis as a potentially emerging dangerous insect pest of groundnut. No available literature on insect pests checklist mentioned Rhyparochromus littoralis as a minor/major pest of groundnut 
prior to this present investigation in Yola. R. littoralis is a devastating pest in groundnut fields that just a small population would multiply within a week and cause great devastation that may lead to 80 percent or more loss in yield of groundnut (Malgwi and Onu, 2004). They feed mainly on the pods by sucking the oil using their stylate. However, there is paucity of details on the description of $R$. littoralis damage on groundnut documented in literature, nor its comparison on different varieties or cultivars of groundnut, except what is being reported in this study. Therefore, the present study was aimed at establishing the damage potential on groundnut and comparing the assessment study of the damages caused by $R$. littoralis on groundnut harvesting days during the 2009 and 2010 cropping seasons in Yola, Adamawa State belonging to the Sudan Savannah Agro-ecological zone in Northeastern Nigeria.

\section{The Study Area}

\section{Materials And Methods}

The field experiment was conducted at the Teaching and Research Farm of the Department of Crop Production and Horticulture of the Federal University of Technology Yola which is located in Sangere village in Girei Local Government Area of Adamawa State within longitude $9^{0} 14^{\prime}$ North and longitude $12^{0} 13^{\prime}$ East of the Equator in the Northern Guinea Savanah agro-ecological zone of Nigeria (Adebayo, 1999).

\section{Experimental Design}

The experiment was set up as a split plot design (SPD) with initial pest density and groundnut types as factors. Treatments were replicated three times. The main treatment was the groundnut cultivar in the main plots while the sub-treatments are the harvesting days. All treatments were replicated three (3) times. Groundnuts were planted $40 \mathrm{~cm}$ between rows with 1 plant/hill, the plant spacing was $25 \mathrm{~cm}$ within rows, again with 1 plant/hill (Shankarappa, et al., 2009). The plot size for the main treatment was $80 \mathrm{~m}$ x $20 \mathrm{~m}$, and the sub-plot was $5 \times 4 \mathrm{~m}$. This gave 15 rows within each sub-plot which made up the required plant population of 133, $000-$ 167, 000 plants per hectare.

\section{Source of Planting Material}

The groundnut cultivar, 'Kampala' which is a late maturing local cultivar was purchased from the Jimeta Ultra Modern Market and was planted during 2009 and 2010 cropping seasons.

\section{Data Collected}

Average establishment of each plot was noted. Plant establishment was carried out 3 weeks after sowing. At maturity, when the groundnut was ready for harvest each sub-plot in the replication was sampled within the main plots to determine the abundance and prevalence of Rhyparochromus littoralis Dist in the following order:

1. Immediately on harvest day (ODAH);

2. 3 days after harvest (3DAH);

3. 7 days after harvest (7DAH);

4. 9 days after harvest (9DAH);

5. 14 days after harvest (14DAH)

6. 21 days after harvest (21DAH);

7. 28 days after harvest (28DAH) and

8. 35 days after harvest (35DAH.)

\section{Sampling Method}

Matured groundnut was harvested within the sub-plot treatments and subjected to nine (9) different levels of destructive sampling. That is, the material nuts was picked immediately after digging up from the ground, and then the remaining harvested groundnuts were left (packed) on the field for 3, 7, 9, 14, 21, 28 and 35DAH. The number of insects on each of the sampled treatments were determined by spraying with Deltamethin + piperonyl butoxide (e. c) insecticides in order to kill/immobilize the insects on the sampled plot, a fine netted linen sheet was used to cover each sprayed sample to prevent the insects from escaping.

Also, on each trial site harvested groundnut was kept hanged on the rope for 3, 7, 9, 14, 21, 28 and 35DAH and observed for the insect infestation. This was done to determine the significant difference between groundnut harvested and left on the ground and that which was packed on a roped. The harvested groundnut pods on each subplots sampled were counted and weighed (unshelled) while the shelled kernels from each subplot were also weighed. A physical observation on the unshelled nut was carried out to see if there were feeding punctures or eggs laid. The same observation was made on the shelled kernels.

The percentage loss was determined by comparing the weight loss of the groundnut that was promptly harvested and dried outside the field with each of the groundnut harvested subsequently and expressed as percentage reduction in yield/ha as described by Malgwi, (2007) as follows:- 
1. \% reduction in yield loss due to infestation by the insect:

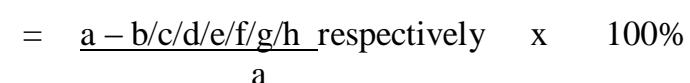

1. \% reduction in yield loss due to infestation by the insect $=\underline{a-b} \times \quad 100 \%$

a

$\begin{array}{lll}\text { Where: } & \\ \mathrm{a} & = & \text { Groundnuts freshly harvested and dried properly outside the field } \\ \mathrm{b} & = & \text { Groundnuts harvested 3DAH } \\ \mathrm{c} & = & \text { Groundnuts harvested 7DAH } \\ \mathrm{d} & = & \text { Groundnuts harvested 9DAH } \\ \mathrm{e} & = & \text { Groundnuts harvested 14DAH } \\ \mathrm{f} & = & \text { Groundnuts harvested 21DAH } \\ \mathrm{g} & = & \text { Groundnuts harvested 28DAH } \\ \mathrm{h} & = & \text { Groundnuts harvested 35DAH }\end{array}$

This was done for both shelled and unshelled groundnut to determine which of the groundnut variety shows significance in weight reduction and whether the shells had less effect on infestation by the bugs.

\section{Statistical Analysis of Field Work}

The data collected were analyzed using analysis of variance (ANOVA) on SAS statistical package using the generalized linear model and significant $\mathrm{p}=0.05$ means was separated using Student Neumann- Keuls (SNK) test for variables.

\section{Yield Loss}

There are several acceptable methods of estimating the loss to stored products. To estimate the damage $(\%)$, each sample was divided into damaged and undamaged pods or kernels and the percentage damage was calculated by using the following formula:

$\begin{array}{ll}\text { Damage }(\%) & \text { Number of damaged pods } \times 100 \\ \text { Total number of pods } & \\ \text { Weight loss }(\%) & =\quad(\mathrm{UNd})-(\mathrm{DNu}) \times 100\end{array}$

$\mathrm{U}(\mathrm{Nd}+\mathrm{Nu})$

Where:

$\mathrm{Nu}=$ No. of undamaged pods; $\mathrm{Nd}=$ No. of damaged pods; $\mathrm{U}=$ Dry mass of undamaged pods $; \mathrm{D}=$ Dry mass of damaged pods (Dick, 1987 and Lale, 2002).

\section{Results \\ Incidences and Relative Abundance of Rhyparochromus liltoralis Dist}

The first set of data collected on pest incidence was at 3 days after harvest (DAH) 2009 and 2010 cropping seasons. The first two methods; picking the groundnut pods on the day the groundnut was dug from the ground (ODAH) recorded no insect pest attack.

The incidence or abundance of $R$. littoralis significantly rose from 3DAH to 28DAH with the least means of 1135.33 and 1274.00 at 3 DAH and 5036.33 and 5079.67 as the highest mean abundance on the 28DAH in 2009 and 2010 respectively as presented graphically in Figure 1, which shows that there was rise in population of the sucking bug with additional number of days that the groundnut was left to dry on the field before decorting. The least observed was on ODAH where the insect pest did not attack the groundnuts. The highest mean populations were recorded on 28DAH for 2009 and 2010 respectively. The least population was recorded on 3DAH as shown on Figure 1.

\section{Weight of Groundnut after Harvest}

The weight of groundnut pods significantly vary from $0 \mathrm{DAH}$ to $35 \mathrm{DAH}$ as it relates to the level of infestation and the length of period the pods were left on the field to dry after digging up from the ground. The highest mean weight in grams was $1767.3 \mathrm{~g}$ in 2009 and 1303.3 in 2010 in the 0DAH and all through there was significant difference within each year as shown on Table 1 . The reduction in weight retrogresses with the increase in number of days the groundnut was left to dry on the ground from ODAH to 35DAH with the value of $1769.3 \mathrm{~g}$ being the highest down through to the least weight of $363.6 \mathrm{~g}$ in the 2009 while in 2010 the same trend occurred with ODAH recording the highest weight of $1503.3 \mathrm{~g}$ until the least weight of $331.0 \mathrm{~g}$ was recorded. These consistencies indicated that the longer the groundnut was left on the ground, the more it became prone to attack by the sucking bug. 
The resultant trend of loss of weight of the unshelled groundnut is directly proportional to the loss of weigh of the shelled groundnut as shown generally in Table 1; the longer groundnuts are left on the field, the more the level of infestation and hence loss in quality and quantity of the kernel.

\section{Damaged caused by $\boldsymbol{R}$. littoralis}

The results on the percentage loss in weight on shelled kernels as a result of damages infested by the groundnut sucking bug $R$. littoralis and the1000 grain weight percentage for the data collected during the 2009 and 2010 cropping seasons showed that there was significant difference in loss of weight with increasing number of days the groundnuts were left on the field to dry. A typical damage in field by R. littoralis on the local cultivar is shown on plate $1 \mathrm{a}$, while the unifested is in plate $1 \mathrm{~b}$.

The groundnut kernel/seeds infested with $R$. littoralis at $28-58 \mathrm{DAH}$ on the field without decorting and then shelled showed that seeds become shriveled, sunken, smaller and unattractive and a sign of secondary infection by soil pathogenic organism. The entry points created by $R$. littoralis could have introduced the secondary pests (soil borne organisms).

Plate 1: Infested kernel and non infested groundnut kernels

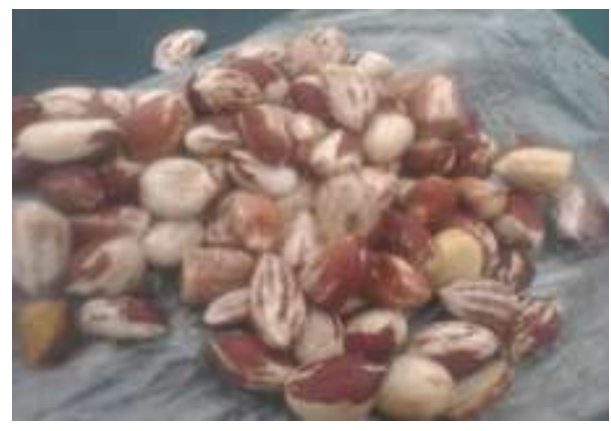

Plate 1b.

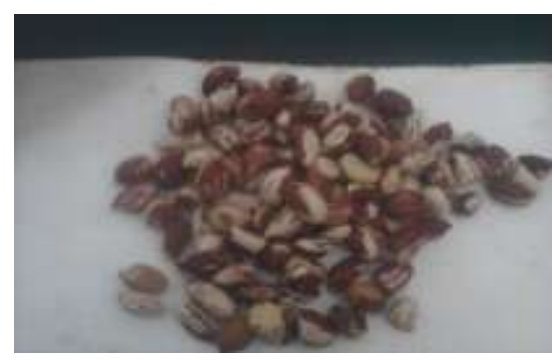

Plate 1a.

Table 1: Mean number of $R$. littoralis abundance in Yola for 2009 and 2010 Cropping Seasons

\begin{tabular}{ccccccc}
\hline $\begin{array}{l}\text { Days } \\
\text { Harvest }\end{array}$ & \multicolumn{2}{c}{$\begin{array}{c}\text { Mean Number of } \\
\text { R. littoralis }\end{array}$} & \multicolumn{2}{c}{$\begin{array}{c}\text { Mean weight of unshelled } \\
\text { groundnut }\end{array}$} & \multicolumn{2}{c}{$\begin{array}{c}\text { Mean weight of shelled } \\
\text { groundnut }\end{array}$} \\
& $\mathbf{2 0 0 9}$ & $\mathbf{2 0 1 0}$ & $\mathbf{2 0 0 9}$ & $\mathbf{2 0 1 0}$ & $\mathbf{2 0 0 9}$ & $\mathbf{2 0 1 0}$ \\
\hline 0DAH & $0.00^{\mathrm{h}}$ & $0.00^{\mathrm{h}}$ & $1769.3^{\mathrm{a}}$ & $1503.3^{\mathrm{a}}$ & $772.0^{\mathrm{a}}$ & $486.0^{\mathrm{a}}$ \\
3DAH & $1135.33^{\mathrm{g}}$ & $1274.00^{\mathrm{g}}$ & $826.3^{\mathrm{b}}$ & $759.7^{\mathrm{b}}$ & $659.3^{\mathrm{a}}$ & $566.0^{\mathrm{a}}$ \\
7DAH & $2540.00^{\mathrm{e}}$ & $2652.33^{\mathrm{e}}$ & $700.0^{\mathrm{bc}}$ & $567.3^{\mathrm{bc}}$ & $467.3^{\mathrm{b}}$ & $403.0^{\mathrm{b}}$ \\
9DAH & $3224.67^{\mathrm{d}}$ & $3445.33^{\mathrm{d}}$ & $657.3^{\mathrm{bc}}$ & $558.8^{\mathrm{bc}}$ & $364.7^{\mathrm{bc}}$ & $287.3^{\mathrm{bc}}$ \\
14DAH & $3776.33^{\mathrm{c}}$ & $3837.33^{\mathrm{c}}$ & $578.3^{\mathrm{bc}}$ & $546.0^{\mathrm{bc}}$ & $355.3^{\mathrm{bc}}$ & $282.3^{\mathrm{bc}}$ \\
21DAH & $4699.67^{\mathrm{b}}$ & $5401.67^{\mathrm{b}}$ & $522.7^{\mathrm{c}}$ & $469.0^{\mathrm{c}}$ & $346.7^{\mathrm{bc}}$ & $264.3^{\mathrm{bc}}$ \\
28DAH & $5036.33^{\mathrm{a}}$ & $5079.67^{\mathrm{a}}$ & $432.0^{\mathrm{c}}$ & $387.7^{\mathrm{c}}$ & $321.3^{\mathrm{c}}$ & $240.0^{\mathrm{c}}$ \\
35DAH & $1728.67^{\mathrm{f}}$ & $1641.67^{\mathrm{f}}$ & $363.7^{\mathrm{c}}$ & $331.0^{\mathrm{c}}$ & $259.7^{\mathrm{c}}$ & $195.3^{\mathrm{c}}$ \\
\hline
\end{tabular}

Means with the same letters in the same column are not significantly different at $\mathrm{P} \leq 0.05$ using Student Keuls Newman (SNK) test for variables.

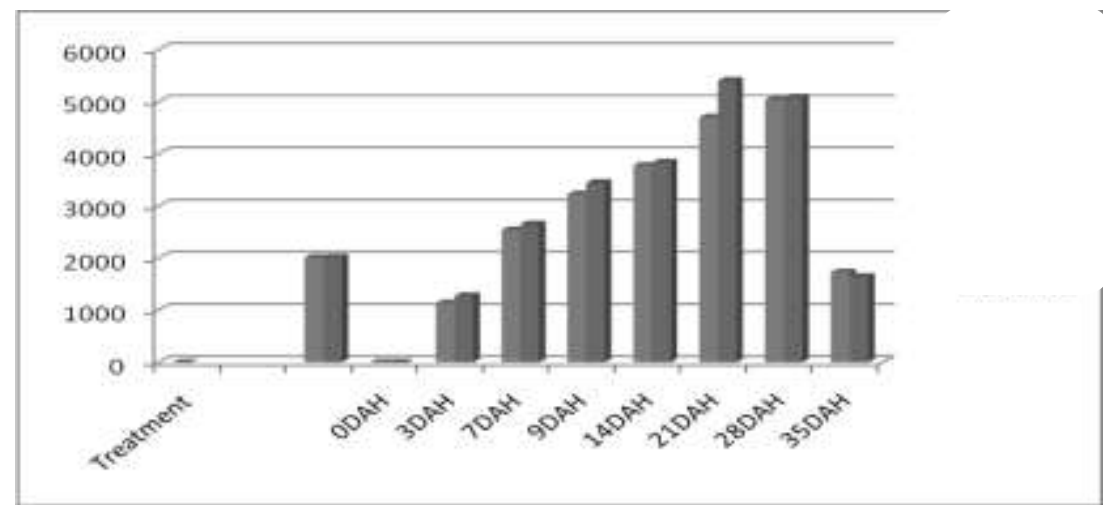

Figure 1: Mean Number of R. littoralis in 2009 and 2010 
$\underline{\text { Key }}$

$\frac{\text { Key }}{\mathrm{DAH}}=$ days after harvest

\section{Discussion}

The results on the abundance of $R$. littoralis is an important step in knowing the abundance of $R$. littoralis Dist, which time of the season or year they appear most and at what stage do they appear in groundnut field and when do they constitute threat to the groundnuts. From the results, there are two factors that encourage the insect build-up (infestation) on the field i.e. the presence of groundnut piles in the field and the number of days that it was left to dry before picking. The three peak period of infestation on the field is after the groundnut is left on the field for 14, 21 and 28 days after harvesting (DAH) before picking. This is an important factor in determining the population and level of infestation of the bugs at a particular harvesting period and time.

The differences that occurred with the two cropping seasons could be due to the environmental factors within the seasons, but it is important to note that there are two peak periods during which $R$. littoralis would strive in piled groundnut during harvest, which could play an important factor in determining when to harvest groundnut from the ground and when to pick up the pods. This knowledge would also play a fundamental role as to how to design a tool for managing or controlling $R$. littoralis, which normally peaks when left to dry on the field for too long before picking.

The average minimum temperature of $31^{0}-32^{\circ} \mathrm{C}$ and a high relative humidity of $75-80 \%$ as observed during this study especially at night when the activity of $R$. littoralis is high, because they are nocturnal in nature. The infestation of $R$. littoralis also depends on the number of days the crop is left on the field to dry prior to picking up of the pods. Although the number of nymphs were not taken in the cause of this study in the field, careful observation noted that more adults were found at $21 \mathrm{DAH}$ and $28 \mathrm{DAH}$ while at 35DAH the number of adult bugs drastically reduces (diminishes) with heavy presence of uncountable number of nymphs. This difference could be due to the biology of $R$. littoralis whose life span appears to be short. As earlier mentioned, these pieces of information are very important for determining the optimum time for which groundnut should be left on the field before harvesting.

On the other hand, the population of $R$. littoralis at the early stage of data collection 3DAH, 7DAH and 9DAH is seen to be very minimal though rises progressively. Insect infestation adversely affected yield and resulted in tremendous reductions of quality and quantity with increasing number of days left on the field to dry. Up to $72 \%$ loss in weight/yield was recorded in 2009 at 35DAH while $68 \%$ of loss weight was recorded in 2010 $\mathrm{V}_{1}$ at the same 35DAH. The least loss in weight of $23.4 \%$ and $24.2 \%$ were recorded in 2009 and 2010 respectively.

The difference in results of 2009 and 2010 cropping seasons could be due to the seasonal fluctuations in weather conditions. Although $R$. littoralis is a small bug whose activity is nocturnal, working on it, was somewhat very difficult as economic importance is yet to be determined, but this study is a step towards actualizing it, since its abundance and time of the year it occurs and at what stage of groundnut production has been identified.

\section{Damage Of $R$. Littoralis On Groundnut}

Results obtained from this study indicated that $R$. littoralis is a potential economic pest, emerging as a serious threat to the harvesting of quality and healthy groundnut pods, and generally groundnut production. Importantly, the bug does not spare any pod in sight as it ravages all leaving behind an almost useless pod where the experiments were carried out.

Research has earlier indicated the presence of $R$. littoralis in Nigeria as reported by Malgwi and Onu (2004) but no serious attention was given to the early warning of the potential threat this bug causes to groundnut. The presence of $R$. littoralis in such concentration as observed within these cropping seasons in Yola points to the fact that the pest probably had unknowingly become a serious threat to groundnut production in this location. It's prevalence and persistence in the study area is seriously enhancing it's ability of increasing its host range other than the groundnut in the study area.

In the present investigation, $R$. littoralis has proved to be a versatile pest hibernating in thrash of groundnut, cowpea, maize, sorghum, millet and sesame in addition to other weed plants; which suggests that once it establish itself, eradication may be difficult locally. This portends a serious threat to the groundnut industry in Nigeria since the oil industry depends on groundnut, which mostly comes from local farmers who know little about the biology and the control measure of the insect and other pests.

The results obtained from 2009 and 2010 cropping seasons showed little or no difference. This suggests that $R$. littoralis has very high ecological ability to adapt easily to any weather condition. This agrees with Smith (2002) and Malgwi (2007) that a versatile insect can easily adapt to a wide range of soil or environmental conditions in the tropics. However, the high percentage of damage done to groundnut resulting in huge loses in groundnut $(70.2 \%)$ as recorded in the present study suggested the fact that R. littoralis has also become a major pest of groundnut in northern Nigeria. 
Although the pest status of $R$. littoralis is yet to be determined, the damage potential determined on groundnut in this study poses a serious threat in term of its damage percentage of above $10 \%$. This further proves that $R$. littoralis is a true pest of groundnut as earlier reported by many other researchers (Onu and Malgwi, 2004; ICRISAT, 2008; Samaila, 2010; Samaila and Malgwi, 2010 and Ranga Rao, et al., 2010). Hitherto, R. littoralis has never been reported elsewhere in Nigeria as being a major pest or threat to groundnut. Results obtained from this investigation indicated that $R$. littoralis is a potential economic pest, emerging as a serious threat to the harvesting of quality and healthy groundnut pods.

\section{Conclusion}

This study has identified $R$. littoralis as a seriously emerging threat to groundnut farming in the study area. This threat is to be taken seriously and adequate measures should be taken by all stakeholders in order to salvage and nip the situation in its bud. As seen in this study, the emergence of the pest is at a crucial and critical stage of groundnut production when farmers have already started to rejoice for overcoming all production hurdles only to be devastated by this post harvest field insect pest. Although no work has been carried out on $R$. littoralist alternate feeding sources, but the findings in this study could serve as an eye opener on its possible alternate hosts. There is also the need to thoroughly investigate this insect pest which will help in developing a comprehensive control of $R$. littoralis, because the pest appears to survive for longer periods on some yet un-identified crops or plants. The families of the weeds that could serve as alternate host plants has to be put into consideration as most of them other than those found, could be potential host plants or alternate host plants where $R$. littoralis is a dormant pest. Care should be taken that such weeds and crop plants are not planted or rotated on the same field.

It can be concluded therefore, $R$. littoralis is a true pest of groundnut and a major emerging threat to groundnut production in Yola in the Northeastern region of Nigeria. The management practices such as digging and picking of pods same day or within three days will assist in avoiding the bug. Alternatively, getting rid of the alternate host plants, clean farm sanitation practice and proper chemical control is suggested to be first step in managing this devastating post harvest field insect pest of groundnut, which is capable of causing yield reduction of upto $90 \%$ in oil content. The identification of its alternate host plants, over seasoning strategy, behaviour, dispersal and other knowledge of its possible habitat or niches are major steps towards understanding and planning an effective management and control programme for its control and probably eradication.

\section{References}

[1] Adebayo, A.A (1999) Climate II. In Adebayo, A. A and Tukur, A.L. (eds) Adamawa State in Maps pp 23-25 Paraclete Publishers, Jimeta - Yola.

[2] Brink, M. and Belay, G. (2006) Plant Resources of East Africa. PROTA Network Office Europe, Wageningen University, P.O. Box 341, 6700 AH Wageningen, Netherlands. 351pp

[3] Dick, K. M. (1987) Pest Management in Stored Groundnut. Information Bulletin No 22. Patancheru, A. P. 502, 324, India: International Crop Research Institute for the semi-Arid Tropics.

[4] Hammons, R.O. (1994) The origin and history of the groundnut. In Smart, J. (ed) The groundnut crop: A scientific basis for improvement. Chapman and Hall, New York. Pp76

[5] ICRISAT (2008) Groundnut Insect Pest- Pod sucking Bug. http.// www.krisat.org/vasat/learning. resource.

[6] ICRISAT, (2009) Annual report Patancheru, Andra Pradesh, India. Patancheru, Andra Pradesh, India.

[7] Johnson, R.A., Lamb, R.W, and Wood, T.G. (1981) Termite damage and crop loss studies in Nigeria - a survey of damage to groundnut. Trop.Pest Manag 27:325 - 342

[8] Malgwi, A. M and Onu, J. I (2004) Insect pest of cowpea and groundnut in Girei Local Government Area, Adamawa State. Nigeria Journal of Entomology (2004) 21: 137 - 151

[9] Malgwi, A. M. (2007) Bioecology, damage potential and control of Cylas puncticollis BOH.(Coleoptera:Brentidae): A New Pest of Cotton in Nigeria. PhD Dissertation submitted to the Postgraduate School, Ahmadu Bello University, Zaria, Nigeria.

[10] Ranga Rao, G. V., Ramashwar Rao, S. and Nyam, S. N. (2010) Post-harvest Insect pests of Groundnut and their Management. Information Bulletin No.84: Patencharu 502 324, Andhra Pradesh, India. International Crops Research Institute for the Semi Arid Tropics. 20pp

[11] Samaila, A. E. (2010) Effects of Cropping Systems and Insecticides on the Abundance of Groundnut Sucking Bug (Rhyparochromus littoralis Dist.) in Song Local Government Area of Adamawa State: A paper presented during the 41st Annual Conference of the Entomological Society of Nigeria, (E S.N) held at the Wesley University of Science and Technology, Ondo Town, Ondo State. October 2010

[12] Samaila, A. E. and Malgwi, A. M. (2010) Survey of the Abundance of the Groundnut Sucking Bug (Rhyparochromus littoralis Dist): A Field and Storage Pest of Groundnut in Adamawa Central Senatorial District being a paper presented during the 41st Annual Conference of the Entomological Society of Nigeria, (E S.N) held at the Wesley University of Science and technology, Ondo Town, Ondo State. October 2010

[13] Shankarappa, T., Robert, E. R and Virginia, N. (2009) World Geography of Groundnut: Distribution, production, use and trade. www.worldgeography/peanut U.S.A. pp. 1-11.

[14] Slater, J. A. (1972) The occurrence of Elasmolomus sordidus a potential pest of Peanut in Brazil (Hemiptera Lygaeidae) Biologica 38: 394 - 397.

[15] Smith, A.F. (2002) Peanuts: The Illustrious History of the Goober Pea. Chicago: University of Illinois Press.

[16] Wood, A. and Ambridge, L (1996) Insect Pests of Nigerian Crops. Natural Resource Institute, Head Publishing and Publicity Group. Maritime, Kent, United Kingdom.pp132 